\title{
A woman whose radiographs showed subcutaneous metallic objects
}

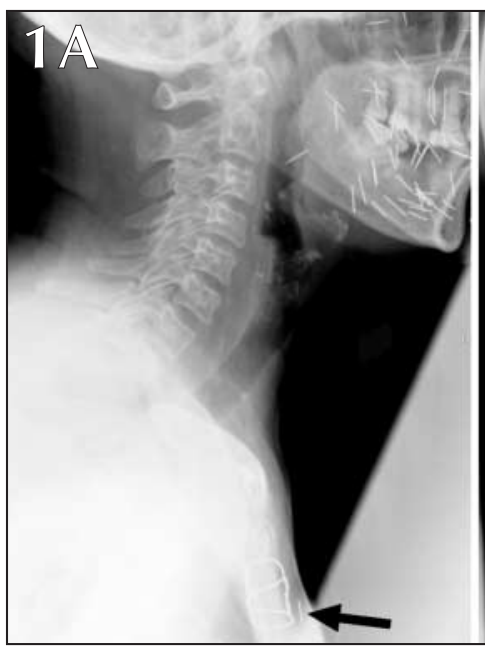

67-year-old Indian Muslim Awoman was admitted with mild occipital headaches preceded by neck pain. She had been experiencing the headaches and neck pain weekly for several years. The woman had a history of hypertension, diabetes mellitus, hyperlipidemia and ischemic heart disease, for which she had undergone coronary artery bypass grafting.

Clinical examination was unremarkable. Cervical spine radiography revealed degenerative changes consistent with cervical spondylosis. In addition, multiple needle-like metallic foreign bodies $1.5 \mathrm{~cm}$ long were seen over her facial and occipital regions (Fig. 1). Two of the needles were also noted in the thorax: one anterior to the sternotomy wires (Fig. 1A, arrow) and the other in the left chest wall (Fig. 1C, arrow). The appearance and distribution of these needles on the radiographs were consistent with "charm needles" or susuks. A $m$ head CT scan obtained earlier $\vec{\sigma}$ had appeared normal apart from the presence of artifacts (not shown), probably from the charm needles.

The needles were not visible on gross examination (Fig. 2). The patient confirmed their
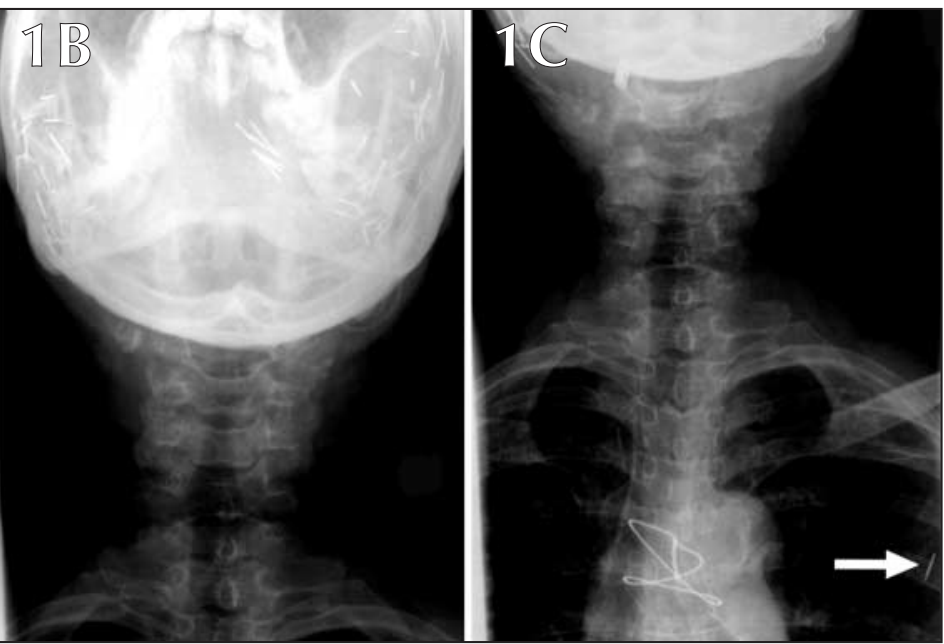

presence and that they had been inserted subcutaneously several decades before her presentation, which ruled them out as a cause of the headaches. The headaches were consistent with cervicogenic headaches, which are more common in women than in men, are of moderate intensity and are associated with signs and symptoms linking it to the neck.

Charm needles, or susuks, are talismans inserted and worn subcutaneously in the face and other parts of the body. They are believed to enhance or preserve the wearer's beauty, youth, charisma, strength or health, or to bring success in business. ${ }^{2}$ The wearing of charm needles is still practised by some people in Southeast Asia, especially Malayan and Muslim females. ${ }^{2}$ These talismans, often made of gold or silver and mixed with copper, are usually inert and do not corrode. ${ }^{2,3}$ In addition, they do not usually cause pain to the wearer.

Although rare, the discovery of charm needles on radiographs may become more frequent given increased travel and immigration from Southeast Asia. An awareness of this practice is im-

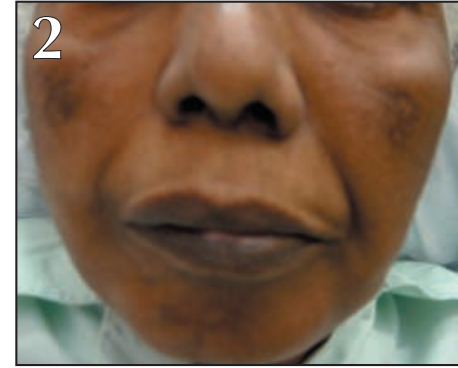

portant to avoid misdiagnosis and mismanagement of these patients. A search of the literature did not reveal any report of untoward effects of talisman insertion, although they have been surgically removed for other reasons. ${ }^{3}$ In the era of MRI, one should consider other imaging modalities in the presence of multiple metallic foreign bodies.

\section{Erle Chuen-Hian Lim}

Tsong-Haur Ng

Raymond Chee-Seong Seet

Department of Medicine

National University Hospital

Singapore

\section{References}

1. Fishbain DA. Cervicogenic headache. Cephalalgia 2002;22:829.

2. Shanmuhasuntharam P, Ghani SH Susuks: charm needles in facial soft tissues. Br Dent 7 1991;170:309-11.

3. Loh FC, Ling SY. Analysis of the metallic composition of orofacial talismans. Oral Surg Oral Med Oral Pathol 1992;73:281-3. 